\title{
APPLICATIONS OF FUZZY MULTIPLE CRITERIA DECISION MAKING METHODS IN CIVIL ENGINEERING: A STATE-OF-THE-ART SURVEY
}

\author{
Zhi WEN ${ }^{1}$, Huchang LIAO ${ }^{1 *}$, Edmundas Kazimieras ZAVADSKAS ${ }^{2}$, \\ Jurgita ANTUCHEVIČIENE ${ }^{3}$ \\ ${ }^{1}$ Business School, Sichuan University, 610064 Chengdu, China \\ ${ }^{2}$ Institute of Sustainable Construction, Vilnius Gediminas Technical University, Vilnius, Lithuania \\ ${ }^{3}$ Department of Construction Management and Real Estate, Vilnius Gediminas Technical University, \\ Vilnius, Lithuania
}

Received 11 September 2020; accepted 14 October 2020

\begin{abstract}
A variety of fuzzy multiple criteria decision making (MCDM) models have been proposed to solve complicated decision-making problems. Many applications have been achieved, especially in the field of civil engineering. To analyze the developments about the fuzzy MCDM methods and their applications in civil engineering in recent years and further explore the future research directions, this study conducts a state of the art survey in which 52 journal papers focusing on the applications of fuzzy MCDM models in civil engineering from 2016 to 2020 are reviewed. We respectively classify these articles according to research problems and research methods. Through the literature review, we get findings in terms of the most concerned decision-making problem, the most widely-used evaluation criterion and the most popular fuzzy MCDM model. Furthermore, we present four aspects of research challenges and corresponding future research directions in the field of civil engineering, which may be helpful for researchers and practitioners to further investigate.
\end{abstract}

Keywords: civil engineering, multiple criteria decision making, fuzzy set, fuzzy multiple criteria decision making, literature review.

\section{Introduction}

Civil engineering is a general name of science and technology for building all kinds of land engineering facilities. On one hand, it refers to the materials and equipment applied and the technical activities such as survey, design, construction, maintenance and repair; on the other hand, it refers to the object of engineering construction, namely, various engineering facilities built on the ground, underground or on land, which directly or indirectly serve human life, production, military and scientific research, such as houses, roads, railways, pipelines, tunnels and bridges, canal, dike, port, power station, airport, offshore platform, water supply and drainage and protection engineering ${ }^{1}$. From the scope of civil engineering, we can see that civil engineering involves a variety of decision-making problems. As Issa et al. (2019) pointed out, multiple criteria

\footnotetext{
${ }^{1}$ https://baike.baidu.com/item/\%E5\%9C\%9F\%E6\%9C\%A8\%E5 \%B7\%A5\%E7\%A8\%8B/389380?fr=aladdin
}

decision making (MCDM) problems in the field of civil engineering are complicated due to the existence of a large number of evaluation criteria and the nature of conflicting among different criteria, such as the conflict between high quality and low cost. MCDM methods are found to be useful tools to solve the decision-making problems in the field of civil engineering (Abdel-malak et al., 2017).

Fuzzy set theory (Zadeh, 1965) is a mathematical theory to represent fuzziness existed in complex systems. Due to the fuzziness and uncertainty of human preference on evaluation objects, Bellman and Zadeh (1970) introduced the fuzzy set theory to solve decision making problems. Henceforth, many MCDM methods have been introduced into the fuzzy environment to solve decisionmaking problems in various fields, among which the civil engineering is no exception. In recent years, various fuzzy MCDM models have been enhanced to solve complex MCDM problems in the field of civil engineering (Leśniak

*Corresponding author. E-mail: liaohuchang@163.com

Copyright $\odot 2021$ The Author(s). Published by Vilnius Gediminas Technical University

This is an Open Access article distributed under the terms of the Creative Commons Attribution License (http://creativecommons.org/licenses/by/4.0/), which permits unrestricted use, distribution, and reproduction in any medium, provided the original author and source are credited. 
et al., 2018; Wieczorek et al., 2019; Hatefi \& Tamošaitiené, 2019; Plebankiewicz et al., 2020; Huang et al., 2020; Fallahpour et al., 2020; Mohandes et al., 2020).

Although a variety of fuzzy MCDM models have been implemented to solve civil engineering problems, there are only a few literature review on these articles. Zavadskas et al. (2017) reviewed the journal articles on the sustainable decision-making in civil engineering, construction and building technology from 2015 to 2017. Different from the review of sustainable decision-making, this paper focuses on making a state-of-the-art survey of the recent applications of fuzzy MCDM methods in civil engineering and further exploring future research directions. Our search strategy is to set the key word "civil engineering" in the Web of Science database, and then use the key word "fuzzy decision-making" to further refine the search results. We captured 146 search records from 2016 to 2020 in August 2020. Among these 146 publications, many of them are not consistent with the research topic of this paper. Some papers were only related to civil engineering, some papers only applied fuzzy set theory, and some papers only used MCDM method. As a result, we elaborately selected 52 relevant literatures which simultaneously focused on fuzzy MCDM methods and their applications in civil engineering from the search results to review. In this paper, we are devoted to reviewing these 52 journal articles published on the applications of fuzzy MCDM models in civil engineering.

We classify these literature according to the decision problems in civil engineering and the criteria related to these decision problems, and divide the fuzzy MCDM models applied in these literature into individual fuzzy MCDM models and hybrid fuzzy MCDM models. Through the literature review and statistical analysis, we get some findings in terms of the most concerned decision-making problem, the most widely-used evaluation criterion and the most popular fuzzy MCDM model. Furthermore, we present four aspects of research challenges and corresponding future research directions in the field of civil engineering, which may be helpful for researchers and practitioners to further investigate.

The rest of the paper is structured as follows: Section 1 classifies the MCDM problems in civil engineering. Section 2 divides the fuzzy MCDM models used in civil engineering into individual fuzzy MCDM models and hybrid fuzzy MCDM models. Section 3 provides observations and recommendations. Section 4 discusses the research limitations and future research directions. Conclusions are drawn in the end of this study.

\section{Classification of multiple criteria decision making problems in civil engineering}

MCDM refers to designing mathematical models to support decision makers' subjective evaluations of alternatives under multiple criteria (Mardani et al., 2015). MCDM problems is a kind of decision-making problems in which the optimal option needs to be found from a set of alter- natives or the feasible alternatives need to be ranked considering multiple non-commeasurable criteria that may conflict with each other. According to the type of evaluation information available for alternatives, MCDM problems can be divided into two categories: multiple criteria discrete alternative problems and multiple criteria optimization problems (Wallenius et al., 2008). The evaluation information involved in the former is usually the performance of each alternative under different criteria, while that of the latter is usually a pairwise comparison matrix of alternatives under each criterion. The latter usually has more alternatives and calculation resources than the former (Wallenius et al., 2008). The corresponding MCDM methods for solving these two kinds of MCDM problems are also divided into two categories: one is based on utility values, such as TOPSIS (Technique for order preference by similarity to ideal solution), VIKOR (Vlsekriterijumska optimizacija i kompromisno resenje in Serbian, meaning multiple criteria optimization and compromise solution), and WSM (Weighted sum model), while the other is based on pairwise comparisons, such as AHP (Analytic hierarchy process), ANP (Analytic network process), and PROMETHEE (Preference ranking organization method for enrichment of evaluations) (Wu \& Liao, 2019).

A variety of MCDM problems exist in the field of civil engineering. After a prescreen, we classify these practical MCDM problems in civil engineering into construction project selection, contractor/supplier selection, personnel selection, material selection, technology selection, location selection, risk assessment, strategy selection, and others. The specific problems and corresponding evaluation criteria are summarized as follows.

Construction project selection: Xiao and Zhang (2016) selected civil engineering public projects and the criteria involve cost of construction, reliability, and life cycle cost to the public. Osei-Kyei and Chan (2017) estimated the success levels of public-private partnership projects and the estimation criteria include cost and technical specifications, profit, effective risk management, reliable and quality service operations, reduced litigations and disputes, environmental performance, and local economic development. Dahooie et al. (2018) selected oil and gas well-drilling projects based on the evaluation criteria including human resource, planning, quality, materials and equipment, number of planned wells, and number of drilled wells. Utama et al. (2019) evaluated international construction projects and the main criteria include project, client, contract, business, and host country.

Contractor/Supplier selection: Plebankiewicz and Kubek (2016) selected construction material supplies and the evaluation criteria include technical expertise, guarantee period, delivery conditions, completion deadline, supplier's reputation, original or substitute, quality of materials, cost within a life cycle, payment conditions, and tender price. Bruno et al. (2016) estimated and selected bogy supplier for rail vehicles to ensure the safety and stability of the vehicle, and the main criteria involve financial position, organization and innovation, service level, and qual- 
ity performance history. Inti and Tandon (2017) selected transport infrastructure contractors by evaluating the sustainability of contractors based on the criteria including quality, safety, reputation, scale of projects completed, insurance, repairs and warranties, tender price, financial references, and financial stability. Nyongesa et al. (2017) evaluated and selected the partner of virtual enterprise associated with construction project, and the main criteria involve management, technical, and business. Taylan et al. (2017) selected contractors for completing construction projects in time and the adopted criteria include reputation, health and safety, management capability, technical ability, and financial situation. Keshavarz-Ghorabaee et al. (2018) evaluated and selected subcontractors for improving the quality of construction projects according to the evaluation criteria such as reliability, schedule-control ability, management ability, and labor quality. Mahamadu et al. (2019) selected the organizations with building information modelling capabilities on construction projects and the criteria include cost, organizational structure, organization experience, technology readiness, reputation, proposed method, specific modelling capacity, technical resources, administrative and strategic capacity, staff experience, and qualification.

Personnel selection: Afshari (2017) selected construction project manager with respect to the criteria including past experience, education, communication skills, computer skills, time management skills, cost management skills, resource management skills, quality management skills, planning skills, organizing skills, controlling skills, problem solving, decision making, and team development. Vo et al. (2018) measured the performance of civil engineers in construction environment and the identified criteria are job implementation skills, cooperation skills, communication skills, planning skills, and knowledge level.

Material selection: Ding et al. (2016) selected the optimal engine for civil aircraft to ensure normal operation of airlines and the considered criteria include sustainability, environmental protection level, competitiveness, economical efficiency, and reliability. Hosseini et al. (2018) selected the best exterior wall for building renovation in earthquake area, and the criteria they used include debrisremoval potential, construction complexity, construction speed, performance cost, and resistance potential against seismic loads. Jato-Espino et al. (2018) selected the materials forming the wearing course in highly trafficked roads and the decision criteria include mechanical resistance, safety, comfort, emissions, consumptions, resource efficiency, and costs. Hafezalkotob et al. (2020) investigated the engineering selection of hybrid vehicle engines and the considered criteria are nitrogen oxides emission, total hydrocarbon emission, carbon monoxide emission, job creation index, relative needed foreign fund, relative price, index of durability and maintenance, fuel consumption, combined ultimate torque, and combined ultimate power.

Technology selection: Omar et al. (2017) selected nondestructive testing technologies to evaluate the condition of reinforced concrete bridge decks and the criteria they used include cost, accuracy, simplicity, speed and capability. Tomczak and Rzepecki (2017) selected the supply chain management systems in civil engineering and the evaluation criteria include warehousing infrastructure costs, the number of reloads, crediting of expenses, the possibility to fulfil emergency orders, and timeliness of deliveries. Jang et al. (2018) assessed the green technologies related to urban infrastructure early in the project life cycle, and the evaluation criteria are the additional construction fee, initial construction fee, utilization rate of reducing construction equipment, utilization rate of recycled materials, utilization rate of eco-friendly construction materials, decreased rate of emissions, success factor of a construction project, and level of human capital. Issa et al. (2019) selected the best surveying technique for solar energy projects and the identified five criteria are saving in costs, ease of use, rate of capture, applicability, and quality of data.

Location selection: Erdoğan and Kaya (2016) determined the most suitable location for the production of nuclear power station and the main criteria involve welfare-related, natural conditions, reliability and safety, economic, and technical. RazaviAlavi and AbouRizk (2017) selected the most desirable site layout planning based on the criteria including facility size, accessibility, safety, and adjacency preferences. Boostani et al. (2018) selected the optimal site for the construction of temporary shelters and the identified criteria are political stability, environmental aspects, social aspects, economic factors, access to energy resources, access to connection networks, centers and other service centers, proximity to relief distribution, proximity to affected areas, telecommunication facilities, land suitability, and infrastructure facilities. Hocine et al. (2020) proposed a weighted-additive fuzzy multi-choice goal programming model to select a suitable renewable energy site and the considered criteria include social acceptability, topography and infrastructure energy generation, and unit cost energy.

Risk assessment: Andrić and Lu (2016) assessed the disaster risk faced by bridge construction for reducing or preventing the adverse consequences of disasters, and the risk factors include terrorist attacks, fire, construction and design, deterioration, overloading, collision, age, soil, ice, scour, debris, floods, hurricanes, tsunamis, and earthquakes. El Chanati et al. (2016) assessed the use risk of water pipelines to minimize health and safety hazards and ensure adequate water supply, and the assessment criteria include breakage rate, pressure coefficient, soil type, ground water level, surface location, installation quality, size, material, and age. Javadi et al. (2017) selected the most important hazards in underground longwall mining to reduce the risk of hazardous consequences of this mining activity, and the considered criteria include consequence, vulnerability, detectability, and reaction. Patel and Jha (2017) determined the most hazardous project hazard index which represents the maximum hazard level of the construction project, and the project hazard indices include tunneling, concrete work, excavation work, 
welding, cutting, and hot work, construction tools and machinery use, lifting and hoisting machinery, erection of steel concrete structure, roof work, false work, and scaffolding and ladder usage. Zhang et al. (2017) assessed the risk of building damage caused by tunnel excavation in the early construction stage, and the main criteria involve tunnel design, geological condition, building condition, and management condition. Satapathy et al. (2018) analyzed the risk factor of physical disorders of construction workers for improving the health status of construction workers, and the evaluation criteria are mainly divided into body movement and body parts. Yu et al. (2018) evaluated the risk factors in transnational public-private partnership projects, and the four categories of risk assessment are partnership risk, technical and natural risk, legal and sociopolitical risk, and financial and commercial risk. Chatterjee et al. (2018) evaluated the risk of construction projects and the risk criteria include political instability, economic risk, social risk, technological risk, work quality risk, time and cost risk, resource risk, documents and information risk, and stakeholder risk. Zolfaghari and Mousavi (2018) prioritized the risks in the execution lifecycle of highway construction projects, and the considered criteria include detection magnitude, severity magnitude, and occurrence magnitude. Mazher et al. (2018) assessed the risks of power and transport infrastructure publicprivate partnership projects, and the critical risk factors include project planning and implementation, project revenue, project finance, public sector maturity, political stability, country economy and government interference. Ilbahar et al. (2018) assessed the risks of construction yard excavation and the assessment criteria are mainly from the five aspects of construction yard management, heavy equipment, non-secure behaviors, staff management, and environmental factors. Rezakhani and Maghiar (2019) estimated the duration degree of risk activities in a simulated bridge project, and the considered criteria are procurement, quality, cost, and scheduling.

Strategy selection: Chen and Pan (2016) selected the best low-carbon building measure to reduce building carbon emissions, and the criteria they used include technical reliability, initial cost, payback period, ease of operation and maintenance, and potential for operational carbon reduction. Zyoud et al. (2016) selected the strategies of reducing water loss for water distribution system in developing countries, and the evaluation criteria include water quality, flexibility potential, reliability of supply, saving of energy, water preservation and reduction of waste, operation and maintenance costs, costs of implementation, and generation of revenue. Martin et al. (2017) selected the optimal construction project delivery way, and the considered criteria are cost, schedule, quality, complexity, scope change, experience, value engineering, financial guarantee, risk management, uniqueness, external approval, project size, and culture. Liang et al. (2017) selected the best bridge route for large-scale infrastructure project, and the evaluation criteria are technology matu- rity, convenience of operation maintenance, infrastructure difficulty and risk, goal correspondence, and overlapping knowledge bases. Zhao et al. (2017) evaluated and selected the innovative business models for sustainable building, and the main criteria involve risk, corporate strategic benefit, cost, and direct financial benefit. Ebrahiminejad et al. (2018) selected a convenient construction method for various construction elements, and the decision criteria include time, cost, quality, carbon dioxide emissions, legal constraints, required initial capital, and design capability. Amini et al. (2018) selected construction designs with sustainability and resiliency, and the considered criteria are ductility, wind-borne, leadership in energy and environmental design scores, lifecycle analysis, story drift, fragility finite-element analysis, material use, and embodied energy. Song et al. (2018) selected the best layout of construction temporary facilities from the perspective of global conflict minimization, and the estimation criteria include environmental impacts, quality, duration, and cost. Yoon and Cha (2018) proposed a systematic algorithm to provide the optimal facility management strategy for commercial office constructions, and the critical criteria include upgrading staff competencies, tenant security, up-to-date plant and equipment, sufficiency and adequacy of replacement components, work execution control, reliability of service, timely responsiveness, quality of service, customer satisfaction, and cost management. Wang and Piao (2019) selected the maintenance strategies of single equipment, and determined the maintenance priority of equipment components in the initial stage of operation, and the main maintenance strategies include reliability, maintainability, economy, and detectability.

Other problems: Maghsoodi and Khalilzadeh (2017) identified the most critical success factor of construction projects to avoid the possible cost of project failure to economic and industrial development, and the main criteria they employed include quality, cost, time and safety. Galende-Hernández et al. (2018) evaluated the rock mass rating before tunnel excavation to support tunnel construction based on the monitor while drilling data, and the criteria include time, water pressure, water flow, rotation pressure, rotation speed, damper pressure, feed pressure, hammer pressure, penetration rate, and hole depth. Alireza and Abimbola (2019) evaluated the uncertain events that have the greatest impact on the construction period of highway construction projects, and the criteria involve technical, social, political, legal, financial, environmental, and economic factors. Gou and Zhong (2019) diagnosed the fault degree of mechanical equipment, and the attribute set are the vibration amplitude at frequency at three frequencies and average amplitude of vibration displacement. Owusu et al. (2020) identified the most critical procurement irregularity in construction project supply chain, and the evaluation criteria include contract monitoring irregularities, compliance irregularities, proceduralirregularities, and administrative-specific. 


\section{Classification of fuzzy multiple criteria decision making models for solving civil engineering problems}

A variety of fuzzy MCDM models have been presented to solve decision-making problems in the field of civil engineering. Based on the number of decision methods used, these models are divided into individual fuzzy MCDM models and hybrid fuzzy MCDM models.

\subsection{Individual fuzzy multiple criteria decision making models}

There are 33 papers used an individual fuzzy MCDM model to solve the decision-making problems in civil engineering.

Fuzzy AHP: Plebankiewicz and Kubek (2016) selected construction material supplies based on the fuzzy AHP method. The authors conducted literature review to identified evaluation criteria. Then, they generated the weights of the criteria using the fuzzy AHP method, ranked the alternatives under each criterion, and aggregated the ranking results to get the final ranking of the alternatives. Andrić and Lu (2016) used the fuzzy AHP method to assess the disaster risk faced by bridge construction. They established the fuzzy judgment matrix based on the Triangular fuzzy number, applied the fuzzy AHP method to estimate the weights of risk factors, and finally determined the ranking of the risk factors. Omar et al. (2017) selected nondestructive testing technologies for evaluating the condition of reinforced concrete bridge decks by the fuzzy AHP method. The linear triangular fuzzy membership functions were used to fuzzified the scale of pairwise comparison matrices. The fuzzy preference program was used to compute the relative importance and check the inconsistency of fuzzified pairwise matrices. The fuzzy AHP method was applied to determine the weights of alternatives and rank the alternatives. Inti and Tandon (2017) evaluated the sustainability of transport infrastructure contractors by the fuzzy AHP method. They used the additive transitivity property of fuzzy preference relations to generate consistent judgments in the shortest time, so as to improve the fuzzy AHP method on the input quantity of comparative information. Satapathy et al. (2018) adopted the fuzzy AHP method to analyze the physical disorders of construction workers. They used the fuzzy sets to express the evaluate information for various types of construction workers and applied the fuzzy AHP method to deduce the weight of each criterion to obtain the ranking of the impact of each evaluation criterion on workers' musculoskeletal disorders. Vo et al. (2018) used the AHP method based on the fuzzy logic to pick out the critical factors in measuring the performance of civil engineers in the construction environment. The evaluation information was expressed via semi qualitative pairwise comparisons. In the process of deriving the weights of performance factors by the fuzzy AHP method, the fuzzy logic was used to transform the obtained fuzzy weights into crisp weights. Jang et al. (2018) assessed the green technologies for ur- ban infrastructure projects by the fuzzy AHP method. They performed literature review to identified green technologies and sustainable performance indices, and applied the way of questionnaire survey to collect the evaluation information of multiple experts on the performance of alternatives. The fuzzy AHP method was used to derive the weights of criteria based on the calculation of the triangular fuzzy numbers. Nyongesa et al. (2017) solved the partner evaluation and selection problem of virtual enterprise associated with construction project based on the fuzzy AHP method. The AHP method was used to handle certain judgment information, and the reduced group fuzzy AHP method was used to handle uncertain judgment information. The results showed that proposed reduced group fuzzy AHP method dealt with the shortcoming that the classical AHP cannot analyze imprecise data and fuzzy AHP needs a lot of steps to get the final result. Tomczak and Rzepecki (2017) evaluated the supply chain management systems in civil engineering by a modified fuzzy AHP method which applied the triangular interval type-2 fuzzy sets to aggregate group preferences of decision-makers. The modified fuzzy AHP method takes into account both the imprecision of linguistic evaluation information and the difference among expert evaluation. Hosseini et al. (2016) selected the best exterior wall for building renovation in earthquake area based on the AHP method and fuzzy logic. The AHP method was used to derive the weights of criteria and the weight of each alternative is obtained under each criterion. The fuzzy logic was used to output the membership function of each alternative by four parts (fuzzification, interference, rule base and defuzzification).

Fuzzy ANP: El Chanati et al. (2016) respectively adopted the AHP, fuzzy AHP, ANP, fuzzy ANP method to assess the performance of water pipelines. These four methods were applied respectively to obtain the weight of each assessment criterion. The results showed that the fuzzy ANP method takes into account the interactions among criteria and the uncertainty of evaluation information, and was the most accurate method among the four methods.

Intuitionistic fuzzy AHP: Yu et al. (2018) applied the intuitionistic fuzzy AHP method to identify and evaluate the risk factors in transnational public-private partnership projects. The intuitionistic fuzzy sets were used to evaluate the occurrence possibility and severity of risk factors, which dealt with the vagueness of judgments and improved the accuracy of evaluation. The intuitionistic fuzzy AHP method was used to determine the importance degrees of the risk factors and rank the risk factors.

Pythagorean fuzzy AHP: Ilbahar et al. (2018) assessed the risks of construction yard excavation by the intervalvalued Pythagorean fuzzy AHP method. The use of linguistic terms and Pythagorean fuzzy sets provided experts large freedom to express their cognition. The intervalvalued Pythagorean fuzzy AHP method combining fuzzy inference system and Fine Kinney method is beneficial to facilitate accurate risk assessment. 
Fuzzy cloud model: Martin et al. (2017) established a forward normal cloud model with normal distribution membership function for the selection of construction project delivery ways. The model ranks alternatives according to the preferences of multiple decision makers, which is helpful to reduce the conflicts among decision makers, and is more flexible than the interval AHP method in fuzziness and randomness.

Fuzzy PROMETHEE: Chen and Pan (2016) used variable fuzzy PROMETHEE method to select the best lowcarbon building measure. The decision process applied the building information modeling as an aid tool for visualizing and coordinating construction, and carried out a dynamic weight allocation based on the relative importance of criteria and the degrees of influence on criteria. The fuzzy PROMETHEE method was employed to determine the preference degree of one measure over another under each criterion by six preference functions.

Fuzzy SAW: Afshari (2017) selected construction project managers based on the fuzzy SAW (simple additive weighting) method. A literature review was first performed to collect criteria, and the Delphi method was used to identify evaluation criteria. The fuzzy linguistic terms were used to evaluate the performance of candidates. The fuzzy SAW method was then used to aggregate the performance of candidates and obtain the ranking of the candidates.

Fuzzy WSM: Ebrahiminejad et al. (2018) selected a convenient construction method based on the fuzzy WSM method. The authors used triangular fuzzy numbers to capture the uncertainty and fuzziness of expert knowledge for each construction method. The membership function was established for each criterion to obtain the performance values of construction methods. The WSM method was applied to aggregate the performance values, and rank the construction methods.

Fuzzy TOPSIS: Liang et al. (2017) employed the fuzzy TOPSIS method to select the best bridge route for largescale infrastructure project. The authors considered both individual and collaborative criteria to evaluate the alternatives and used different linguistic scales for the two kinds of criteria. The fuzzy TOPSIS method was combined with the weights of criteria given by experts to rank the alternatives. Maghsoodi and Khalilzadeh (2017) used the fuzzy TOPSIS method to identify the most critical success factor by ranking the critical success factors of construction projects. They determined the critical success factors of the construction project based on the literature survey and derived criteria weights by the fuzzy Shannon entropy-based method which made the results reliable. Javadi et al. (2017) selected the most important hazard in underground longwall mining by the fuzzy TOPSIS method. A questionnaire survey was conducted to obtain the evaluation information and criteria weights using linguistic variables. The fuzzy TOPSIS method was used to compute the closeness coefficient of each alternative and then rank the alternatives. Mahamadu et al. (2019) evaluated the building information modelling capabilities of organizations on construction projects by the fuzzy TOPSIS method. The evaluation criteria were identified by the Delphi method, and the weights of criteria were generated in the way of survey. The triangular fuzzy number was used to handle the linguistic evaluation information, and the fuzzy TOPSIS method was applied to rank organizations.

Intuitionistic fuzzy TOPSIS: Song et al. (2018) introduced the intuitionistic fuzzy TOPSIS method to select the best layout of construction temporary facilities from the perspective of global conflict minimization. The authors proposed a multistake-holder conflict minimization-based framework to minimize conflicts between facility layout planner and other stakeholders. The elimination method was implemented to eliminate infeasible alternatives. The intuitionistic fuzzy TOPSIS method was used to obtain a balanced solution.

Fuzzy synthetic evaluation method: Osei-Kyei and Chan (2017) estimated the success level of public-private partnership projects based on a fuzzy synthetic evaluation method. The factor analysis technique was used to extract critical criteria from a large number of collected criteria. The mean score ranking was used to deduce the importance of each criteria. The fuzzy synthetic evaluation method was used to calculate the project success index and rank public-private partnership projects. Yoon and Cha (2018) proposed a systematic algorithm to provide the optimal facility management strategy for commercial office constructions. The authors established a performance evaluation index system of facility management, and adopted a seven-point Likert scale to estimate the performance of criteria. The fuzzy synthetic evaluation method and a balanced scorecard were used to compute the performance index of facility management. Next, the optimal facility management strategy was determined according to the performance index of facility management. Owusu et al. (2020) identified the most critical procurement irregularity in construction project supply chain based on the fuzzy synthetic evaluation method. The questionnaire survey and snowballing methods were conducted to collect a list of criteria, and the mean index analysis was used to generate the relative importance of criteria. The fuzzy evaluation matrix was formed by the membership function and weighting function. The overall criticality index was calculated to determine the most critical irregularities.

Fuzzy programming: Hocine et al. (2020) proposed a weighted-additive fuzzy multi-choice goal programming model to select a suitable renewable energy site. The authors presented an objective function to minimize the weighted sum of normalized deviations, so that the model can use any minimization process of any objective programming variable. Due to the uncertainty of the MCDM problem, the authors applied membership functions to express the fuzziness in the model.

Fuzzy EDAS method: Keshavarz-Ghorabaee et al. (2018) introduced a fuzzy dynamic group MCDM approach to evaluate subcontractors for improving the quality of construction projects. The approach determined the overall performance of alternatives based on the dynamic 
fuzzy EDAS (evaluation based on distance from average solution) method. In the approach, the set of decision makers, alternatives and criteria can be changed at different time periods.

ANFIS model: Utama et al. (2019) introduced an ANFIS (adaptive neuro fuzzy inference system) model to evaluate the international construction projects. The model was based on the fuzzy logic and ANN (artificial neural network) techniques, and the Delphi method was used to collect the evaluation criteria provided by experts. The root mean square error and correlation coefficient were used to measure the performance of the ANFIS model. Meanwhile, Alireza and Abimbola (2019) used the ANFIS model to estimate the uncertain event that has the greatest impact on the construction period of highway construction projects. This method was combined with the size matrix method to learn, model and predict human cognition, which can accurately evaluate and predict the impact of uncertain events.

Fuzzy aggregation method: In addition to the above MCDM methods, several literatures used fuzzy aggregation operators to solve MCDM problems in the field of civil engineering. Xiao and Zhang (2016) solved the selection problem of the civil engineering public project by an induced intuitionistic linguistic ordered weighted averaging distance operator which considered the attitude characteristic of a decision maker. RazaviAlavi and AbouRizk (2017) selected the most desirable site layout planning based on a weighted distance function for construction projects. Rezakhani and Maghiar (2019) used the fuzzy weighted average operator based on the Karnik-Mendel algorithm to estimate the duration degree of risk activities in a simulated bridge project. Gou and Zhong (2019) used the single-valued neutrosophic power weighted averaging operator to diagnose the fault degree of mechanical equipment.

\subsection{Hybrid fuzzy multiple criteria decision making models}

There are 19 papers used a hybrid fuzzy MCDM model to solve the decision-making problems in civil engineering.

Zyoud et al. (2016) integrated the fuzzy AHP with fuzzy TOPSIS methods to select the strategies of reducing water loss for water distribution system in developing countries. Triangular fuzzy numbers were used to express judgments and evaluation information. The fuzzy AHP method was adopted to obtain the criterion weight vector, and the fuzzy TOPSIS method was employed to determine the ranking of alternatives. Erdoğan and Kaya (2016) combined the interval type-2 fuzzy AHP and interval type-2 fuzzy TOPSIS methods to determine the most suitable location for the production of nuclear power. The interval type-2 fuzzy AHP method was developed to derive the weights of criteria, and the interval type-2 fuzzy TOPSIS method was applied to obtain the ranking of alternatives. Taylan et al. (2017) selected contractors for completing construction projects in time based on the fuzzy AHP and fuzzy TOPSIS methods. The fuzzy AHP method was used to determine criteria weights, in which the pairwise comparison information provided by multiple experts was summarized and homogenized. The fuzzy TOPSIS method was applied to obtain the performance of contractors under big data environment. Jato-Espino et al. (2018) developed a decision support model based on the AHP and fuzzy TOPSIS methods for the selection of materials forming the wearing course in highly trafficked roads. The model used the hierarchical decision-making tree to give evaluation criteria, and applied the generalized reduced gradient algorithm to ensure the consistency of pairwise comparison matrices. The AHP method and distance-based aggregation approach were used to derive the weights of criteria according to the information provided by the multiple experts. Fuzzy logic and Monte Carlo simulations were adopted to handle qualitative and quantitative criteria, respectively. The TOPSIS method was employed to obtain the ranking of alternatives. Issa et al. (2019) combined the AHP with fuzzy TOPSIS so as to select the best surveying technique for solar energy projects. The AHP method was used to handle precise, qualitative and quantitative data and generate the relative weights of criteria, while the fuzzy TOPSIS method was used to rank alternatives. The fuzzy agent-based modeling technique was selected to simulate the proposed model. Wang and Piao (2019) developed a facility risk assessment and maintenance system model to select maintenance strategies for a single piece of equipment based on the AHP and fuzzy TOPSIS methods. The authors used the AHP method to select maintenance criteria and determine the weight of these criteria, and applied the fuzzy TOPSIS method to aggregate the scores of alternatives. In the decision-making process, the FMEA (failure mode and effects analysis) method was used to establish decision matrix. They also guided the maintenance processes by the building information modeling and augmented reality technique.

Ding et al. (2016) selected the optimal engine for civil aircraft to ensure normal operation of airlines based on the utility theory and AHP method. The AHP method was applied to generate the weights of criteria. The piecewise utility functions were used to determine the utility values of engines over each criterion. The ranking of engines was obtained by calculating the weighted utility values of each engine.

Patel and Jha (2017) employed the fuzzy measures, fuzzy integrals, fuzzy AHP, and WSM to evaluate the project hazard index which represents the hazard level of the construction project. The Delphi method was used to collect and identify alternatives and measurement criteria. The questionnaire survey was carried out to determine the weights of the collected criteria and delete partially unimportant criteria according to the weight information. The fuzzy measures and fuzzy integrals were adopted to determine the relative importance of criteria. The fuzzy AHP was used to derive the weights of alternatives, and the WSM was used to calculate the project hazard index for determining the most hazardous alternative. 
Zhao et al. (2017) evaluated and selected the innovative business models for sustainable buildings based on the AHP and ANP methods. The criteria were identified by literature review and questionnaire survey. The AHP and ANP methods were employed to deduce the weights of criteria, which considered the interdependence among criteria. The nonadditive fuzzy integral was adopted to aggregate the evaluation score of each model.

Zhang et al. (2017) integrated the fuzzy matter-element, Dempster-Shafer evidence theory, and Monte-Carlo simulation to assess the risk of building damage caused by tunnel excavation in the early construction stage. The fuzzy matter-element was used to express the fuzziness and incompatibility information. The Dempster-Shafer evidence theory was combined with the weighted average rule to fuse the evaluation information under the criteria (there may be conflicts among them). The Monte-Carlo simulation was conducted to transform the membership degrees of fuzzy sets into crisp values.

Chatterjee et al. (2018) applied a hybrid fuzzy DANP-MABAC model to evaluate the risk of construction projects. The model combined the D-numbers and ANP method to deal with fuzzy information and determine the weights of criteria. Then, this model was combined with D-numbers and the MABAC (multi-attributive border approximation area comparison) method to determine the alternative ranking and select the best one.

Dahooie et al. (2018) integrated the fuzzy Delphi, SWARA (step-wise weight assessment ratio analysis) and interval-valued fuzzy ARAS (additive ratio assessment) methods to evaluate oil and gas well-drilling projects. The authors applied the fuzzy Delphi method to develop a comprehensive list of criteria and used the interval-valued fuzzy sets to express the ambiguity and uncertainty information. The SWARA and ARAS methods were used to determine criteria weights and rank the alternatives, respectively.

Mazher et al. (2018) combined the fuzzy measure and non-additive fuzzy integral with arithmetic mean to assess the risks of power and transport infrastructure public-private partnership projects. Before evaluating the risks, the authors used fuzzy sets to depict the degrees of risks, and then identified the critical risk factors. They aggregated the risk attribute scores by the Choquet fuzzy integral, which considered the complex interactions between risk factors.

Bruno et al. (2016) estimated and selected the bogies for rail vehicles to ensure the safety and stability of the vehicle based on the AHP method and fuzzy set theory. The AHP method was used to derive the crisp weights of criteria. The fuzzy set theory was applied to obtain the fuzzy performance value of each alternative by depicting the membership function of each criterion. The weighted fuzzy operator was adopted to aggregate the crisp weights and fuzzy performance, and the fuzzy preference index was calculated as the basis of ranking alternatives.

Zolfaghari and Mousavi (2018) presented a failure mode and effect analysis model based on hesitant fuzzy information to prioritize the risks in the execution lifecycle of highway construction projects under uncertain conditions. The authors applied the hesitant fuzzy VIKOR, hesitant fuzzy Shapley-VIKOR, and extended hesitant fuzzy Shapley-VIKOR methods to determine the rankings of project risks. The De-Novo multi-approaches multi-attributes model was introduced to overcome the problem of rank reversal and obtain an accurate ranking.

Amini et al. (2018) selected construction designs with sustainability and resiliency based on an integrated model. The authors used the interval TOPSIS method to obtain the weighted normalized values, applied the simulation method to generate multiple decision matrices according to the random values in each interval, and employed the original TOPSIS method to rank alternatives for each decision matrix. The optimal construction design was determined by the distribution of all ranking results.

Boostani et al. (2018) integrated the fuzzy Delphi, ANP based on fuzzy DEMATEL (Decision making trial and evaluation laboratory), and linear assignment method to select the optimal site for the construction of temporary shelters. The fuzzy Delphi method was applied to identify the main criteria and sub-criteria. The fuzzy DEMATELbased ANP method was used to determine the weights of identified criteria. The linear assignment method was used to rank the shelter sites.

Galende-Hernández et al. (2018) introduced a methodology based on the monitor while drilling data to evaluate the rock mass rating before tunnel excavation to support tunnel construction. The authors adopted unsupervised feature extraction techniques to allow for the unavailability or unreliability of the evaluation information provided by experts, considered several clustering algorithms to get different categories of hole drillings, and used two genetic fuzzy algorithms (scatter iterative rule learning and linguistic iterative rule learning) to make predictions for design parameters during tunneling. The regular increasing monotone quantifier and OWA (ordered weighted average) operator were applied to determine the optimal combination of the variable selection, clustering and prediction algorithms.

\section{Observations}

Section 2 reviewed 52 journal articles on the applications of fuzzy MCDM methods in civil engineering from 2016 to 2020 in terms of the problems and their corresponding criteria and the used MCDM methods. In this section, we present some observations on these articles followed by the above review.

\subsection{Popular decision problems and common evaluation criteria}

In our data set, 12 papers (23.08\%) were associated with risk assessment problems. Regarding the risk assessment of constructions and construction materials, the commonly used criteria are age, design, natural disasters, breakage rate, and conditions. In terms of the risk assessment of construction projects, the commonly used criteria are risk of work activities, economic risk, quality risk, cost risk, 
and planning risk. 10 papers $(19.23 \%)$ were about strategy selection problems. The commonly used criteria are potential, reliability, costs, ease of operation maintenance, risk, experience, quality, and environmental impacts. 7 papers (13.46\%) dealt with contractor/supplier selection problems. The commonly used criteria are quality, safety, reputation, financial stability, costs, tender price, technical, management ability, reliability, experience, and technical. 4 papers $(7.69 \%)$ solved technology selection problems. The commonly used criteria are costs, speed, and simplicity. 4 papers (7.69\%) handled material selection problems. The commonly used criteria are efficiency, costs, emission, consumption, and resistance. 4 papers $(7.69 \%)$ were related to construction project selection problems, and the common evaluation criteria are cost, quality, profit, and reliability. 4 papers $(7.69 \%)$ dealt with location selection problems. The commonly used criteria are economic, safety, and social acceptability. 2 papers $(3.85 \%)$ were about personnel selection problems. The commonly used criteria are cooperation skills, communication skills, planning skills, and knowledge level, and if it is about manager selection, various management skills need to be taken into account. 5 papers $(9.62 \%)$ solved the other decision-making problems in civil engineering, and the used criteria vary. Figure 1 and Table 1, respectively, shows the distribution of decision-making problems in civil engineering and the corresponding frequently used criteria to make the statistical information display clearly. According to the above statistical analysis, we can see that risk assessment is the most popular decision-making problem and cost is the most commonly considered criterion in civil engineering.

\subsection{Popular fuzzy multiple criteria decision making methods}

In our data set, 23 papers (44.23\%) used the fuzzy AHP method to derive the relative importance of alternatives or weights of criteria. 12 papers $(23.08 \%)$ used the fuzzy TOPSIS method to obtain the relative closeness coefficients of alternatives. 4 papers (7.69\%) used the fuzzy ANP method to consider the interaction among criteria and deduce the weights of criteria. 3 papers (5.77\%) adopted the fuzzy synthetic evaluation method to estimate the comprehensive performance of alternatives. 2 papers $(3.85 \%)$ used the fuzzy WSM method to determine ranking of alternatives. The quantity ranking of fuzzy MCDM methods widely applied in civil engineering is shown in Figure 2.

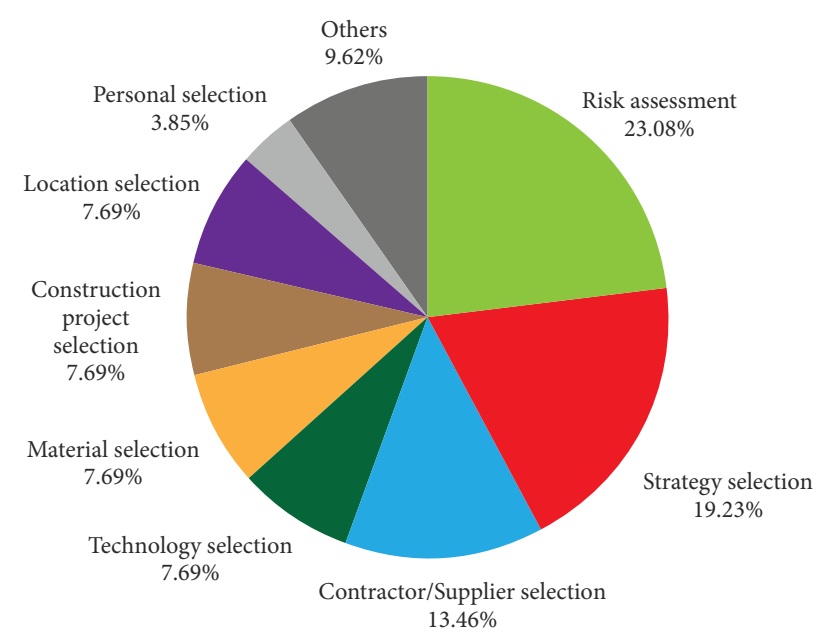

Figure 1. The distribution of decision-making problems in civil engineering

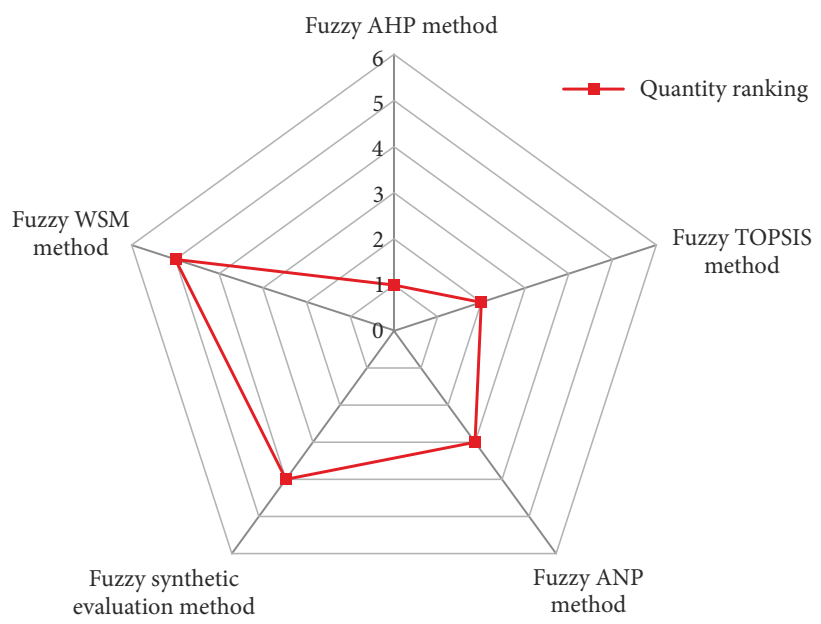

Figure 2. The quantity ranking of fuzzy MCDM methods widely applied in civil engineering

Table 1. The commonly-used criteria involved in the decision-making problems in civil engineering

\begin{tabular}{|l|l|}
\hline \multicolumn{1}{|c|}{ Decision-making problems } & \multicolumn{1}{c|}{ The commonly used criteria } \\
\hline Risk assessment & $\begin{array}{l}\text { Constructions and construction materials: age, design, natural disasters, breakage rate, and } \\
\text { conditions }\end{array}$ \\
\cline { 2 - 3 } & Construction projects: risk of work activities, economic risk, quality risk, cost risk, and planning risk \\
\hline Strategy selection & $\begin{array}{l}\text { Potential, reliability, costs, ease of operation maintenance, risk, experience, quality, and } \\
\text { environmental impacts }\end{array}$ \\
\hline Contractor/Supplier selection & $\begin{array}{l}\text { Quality, safety, reputation, financial stability, costs, tender price, technical, management ability, } \\
\text { reliability, experience, and technical }\end{array}$ \\
\hline Technology selection & Costs, speed, and simplicity \\
\hline Material selection & Efficiency, costs, emission, consumption, and resistance \\
\hline Construction project selection & Cost, quality, profit, and reliability \\
\hline Location selection & Economic, safety, and social acceptability \\
\hline Personnel selection & Cooperation skills, communication skills, planning skills, and knowledge level \\
\hline
\end{tabular}


In individual fuzzy MCDM model, 13 papers (25\%) used the fuzzy AHP method, 5 papers (9.62\%) adopted the fuzzy TOPSIS method, 1 paper (1.92\%) used the fuzzy ANP method, and 3 paper (5.77\%) applied the fuzzy synthetic evaluation method. Moreover, 4 papers (7.69\%) used weighted aggregation operators to aggregate the criteria weight and alternative performance so as to obtain the alternative ranking. 2 papers (3.85\%) adopted the fuzzy synthetic evaluation method to estimate the comprehensive performance of alternatives. 2 papers (3.85\%) adopted the adaptive neuro fuzzy inference system model to attain decision results in accordance with DM cognition. 7 papers respectively applied the fuzzy WSM method, fuzzy SAW method, fuzzy PROMETHEE method, fuzzy EDAS method, weighted-additive fuzzy multi-choice goal programming model and forward normal cloud model to obtain the ranking of alternatives.

In hybrid fuzzy MCDM model, 4 papers (7.69\%) used the fuzzy AHP method, 7 papers (13.46\%) adopted the fuzzy TOPSIS method, 3 papers (5.77\%) applied the fuzzy ANP method, 6 (11.54\%) papers combined the AHP or fuzzy AHP method with the fuzzy TOPSIS method. Moreover, 4 papers respectively employed the fuzzy DEMATEL method, fuzzy SWARA method, interval BWM, and Choquet fuzzy integral approach to deduce criteria weights, and 5 papers respectively used the fuzzy WSM, fuzzy MABAC, fuzzy VIKOR, fuzzy ARAS, and fuzzy MULTIMOORA methods to ascertain the optimal alternative.

Besides, in terms of the collection of decision information, most of the reviewed literature used the questionnaire survey and fuzzy Delphi method. In terms of expressing and processing fuzzy information, 31 papers (59.62\%) used traditional fuzzy sets to transform linguistic terms into triangular fuzzy numbers and further calculated them with membership functions. other papers used interval sets, intuitionistic fuzzy sets, interval-valued Pythagorean fuzzy sets, interval type-2 fuzzy sets, D-numbers, or hesitant fuzzy sets to express and handle uncertain information.

According to the above statistical analysis, we can find that the most popular individual fuzzy MCDM model was based on the fuzzy AHP method, and the fuzzy AHP method is often combined with fuzzy TOPSIS method as a hybrid fuzzy MCDM model.

\section{Challenges and future research directions on decision making in the field of civil engineering}

Through the above literature review and statistical analyses, the applications of fuzzy MCDM methods in civil engineering have been revealed. This section mainly puts forward the research challenges and directions for future research on these challenges.

\subsection{Challenges of existing achievements}

From the review, we can find that there are still some challenges regarding the applications of fuzzy MCDM models in civil engineering:
- The expression tools of fuzzy evaluation information need to be diversified. Generally, the decision results come from the operations over the evaluation information. Since there are various criteria in the decision-making problems of civil engineering, it would be helpful to improve the quality of decisionmaking results by using a variety of evaluation tools when evaluating the alternatives under various criteria. In many reviewed literatures, the evaluation information was limited in the expression of single linguistic terms or interval linguistic terms, which may limit evaluators to express their cognition.

- The interactions among evaluation criteria were seldom considered in the process of determining the weights of criteria. There are many evaluation criteria involved in the decision-making problems of civil engineering. Those criteria may have interactive relationships which have an impact on the assignment of criteria weights (Mazher et al., 2018). However, in the reviewed papers, most fuzzy MCDM models default that the criteria were independent of each other, which may lead to unreasonable decisionmaking results.

- The fuzzy MCDM methods need to be further investigated to meet wider requirements. The AHP and TOPSIS methods are classic and popular MCDM methods, which solved more than half of the civil engineering decision-making problems in the reviewed literature. Nevertheless, with the development of various new decision-making methods in recent years, many MCDM methods with higher accuracy than these two methods could be further extended and implemented in solving civil engineering problems.

- The developments and applications of hybrid fuzzy MCDM models are relatively few. The decisionmaking problems involved in civil engineering are usually complex, and hybrid fuzzy MCDM models are more suitable for solving such problems than individual fuzzy MCDM models, because the hybrid models are the synthesis of multiple individual models, and the accuracy of the decision results obtained by the hybrid fuzzy MCDM models are higher than those derived from the individual fuzzy MCDM models to a certain extent. However, it can be found from the review that the hybrid fuzzy MCDM models are less than the individual fuzzy MCDM models applied in civil engineering.

\subsection{Directions for future research}

In response to the above challenges, we provide four directions for future research on the applications of fuzzy MCDM models in civil engineering:

- It would be interesting to utilize various fuzzy information expression tools to represent evaluation information. In recent years, some effective fuzzy information expression tools have been proposed and widely applied, such as the neutrosophic linguistic 
term set (Smarandache, 2015), hesitant fuzzy linguistic term set (Rodríguez et al., 2012; Liao et al., 2014), probabilistic linguistic term set (Pang et al., 2016) and continuous interval-valued linguistic term set (Liao et al., 2018). In the existing literature, these information expression tools have not been used to solve decision-making problem in civil engineering. Hence, these tools can be used to express evaluation information related to civil engineering.

- Comprehensive methods can be introduced to determine the weights of criteria. These methods can combine the characteristics of the ANP method and BWM (best worst method) (Mi et al., 2019). It can not only consider the interactions among criteria on the basis of the ANP method, but also can improve the consistency of evaluation information by reducing the pairwise comparison times of AHP method like the BWM.

- Applying newly proposed MCDM methods with multiple advantages to solve the decision-making problem in civil engineering would be a good research topic. For instance, the GLDS (gained and lost dominance score method) method (Liao \& Wu, 2020) can be applied to solve the decision-making problems that need to compare alternatives in pairs; the DNMA (double normalization-based multiple aggregation) method (Liao \& Wu, 2020) can be applied to solve the decision-making problem that need to calculate the utility values of alternatives.

- It would be also interesting to develop more hybrid fuzzy MCDM models to solve the decision-making problems in civil engineering. These models not only use different fuzzy information expression tools to evaluate the alternative performance under different types of criteria, but also consider the interactions among criteria to determine the criteria weights, and combine several decision-making methods with good properties to comprehensively determine the decision-making results.

\section{Conclusions}

This paper focused on reviewing 52 literature on the applications of fuzzy MCDM models in civil engineering from 2016 to 2020. First, we classified the literature according to the decision problems in civil engineering and extracted the criteria related to these decision problems. Next, we divided the fuzzy MCDM models used in civil engineering into individual fuzzy MCDM models and hybrid fuzzy MCDM models. Based on the literature review and statistical analysis, we found that the most concerned decision problem is risk assessment, the most widely used evaluation criterion is cost, the most popular individual fuzzy MCDM model is fuzzy AHP, and the most popular hybrid fuzzy MCDM model is the combination of fuzzy AHP and fuzzy TOPSIS. We presented four research challenges related to the applications of fuzzy MCDM models in civil engineering and provided corresponding directions of future research, which is helpful for researchers and practitioners in the field of civil engineering to further investigate.

\section{Funding}

The work was supported by the National Natural Science Foundation of China under Grant 71771156, 71971145.

\section{Author contributions}

Zhi WEN, Huchang LIAO and Edmundas Kazimieras ZAVADSKAS proposed the original idea and conceived the study. Zhi WEN, Huchang LIAO and Jurgita ANTUCHEVICIENE were responsible for developing the method, collecting and analyzing the data. Zhi WEN and Huchang LIAO were responsible for data interpretation. Zhi WEN and Huchang LIAO wrote the first draft of the article. Edmundas Kazimieras ZAVADSKAS and Jurgita ANTUCHEVICIENE revised the paper.

\section{Disclosure statement}

The authors have no competing financial, professional, or personal interests from other parties that are related to this paper.

\section{References}

Abdel-malak, F. F., Issa, U. H., Miky, Y. H., \& Osman, E. A. (2017). Applying decision-making techniques to civil engineering projects. Beni-Suef University Journal of Basic and Applied Sciences, 6(4), 326-331.

https://doi.org/10.1016/j.bjbas.2017.05.004

Afshari, A. R. (2017). Methods for selection of construction project manager: Case study. Journal of Construction Engineering and Management, 143(12), 06017003.

https://doi.org/10.1061/(ASCE)CO.1943-7862.0001400

Alireza, M., \& Abimbola, W. (2019). Key uncertainty events impacting on the completion time of highway construction projects. Frontiers of Engineering Management, 6, 275-298. https://doi.org/10.1007/s42524-019-0022-7

Amini, M., Zhang, B., \& Chang, S. (2018). Selecting building designs with consideration of sustainability and resiliency. Journal of Architectural Engineering, 24(1), 04018001. https://doi.org/10.1061/(asce)ae.1943-5568.0000298

Andrić, J. M., \& Lu, D. G. (2016). Risk assessment of bridges under multiple hazards in operation period. Safety Science, 83, 80-92. https://doi.org/10.1016/j.ssci.2015.11.001

Bellman, R. E., \& Zadeh, L. A. (1970). Decision-making in a fuzzy environment. Management Science, 17(4), 141-164. https://doi.org/10.1287/mnsc.17.4.B141

Boostani, A., Jolai, F., \& Bozorgi-Amiri, A. (2018). Optimal location selection of temporary accommodation sites in Iran via a hybrid fuzzy multiple-criteria decision making approach. Journal of Urban Planning and Development, 144(4), 04018039.

https://doi.org/10.1061/(ASCE)UP.1943-5444.0000479 
Bruno, G., Esposito, E., Genovese, A., \& Simpson, M. (2016). Applying supplier selection methodologies in a multi-stakeholder environment: A case study and a critical assessment. Expert Systems with Applications, 43, 271-285. https://doi.org/10.1016/j.eswa.2015.07.016

Chatterjee, K., Zavadskas, E. K., Tamošaitienè, J., Adhikary, K., \& Kar, S. (2018). A hybrid MCDM technique for risk management in construction projects. Symmetry, 10(2), 46. https://doi.org/10.3390/sym10020046

Chen, L., \& Pan, W. (2016). BIM-aided variable fuzzy multicriteria decision making of low-carbon building measures selection. Sustainable Cities and Society, 27, 222-232. https://doi.org/10.1016/j.scs.2016.04.008

Dahooie, J. H., Zavadskas, E. K., Abolhasani, M., Vanaki, A., \& Turskis, Z. (2018). A novel approach for evaluation of projects using an interval-valued fuzzy additive ratio assessment (ARAS) method: A case study of oil and gas well drilling projects. Symmetry, 10(2), 45.

https://doi.org/10.3390/sym10020045

Ding, S. B., Wang, X. L., \& Wang, H. Y. (2016). Engine selection based on utility theory. Transactions of Nanjing University of Aeronautics \& Astronautics, 33(6), 639-646.

Ebrahiminejad, M., Shakeri, E., Ardeshir, A., \& Zarandi, M. (2018). An object-oriented model for construction method selection in buildings using fuzzy information. Energy and Buildings, 178, 228-241.

https://doi.org/10.1016/j.enbuild.2018.08.002

El Chanati, H., El-Abbasy, M. S., Mosleh, F., Senouci, A., Abouhamad, M., Gkountis, I., Zayed, T., \& Al-Derham, H. (2016). Multi-criteria decision making models for water pipelines. Journal of Performance of Constructed Facilities, 30(4), 04015090 . https://doi.org/10.1061/(ASCE)CF.1943-5509.0000842

Erdoğan, M., \& Kaya, İ. (2016). A combined fuzzy approach to determine the best region for a nuclear power plant in Turkey. Applied Soft Computing, 39, 84-93. https://doi.org/10.1016/j.asoc.2015.11.013

Fallahpour, A., Wong, K. Y., Rajoo, S., Olugu, E. U., Nilashi, M., \& Turskis, Z. (2020). A fuzzy decision support system for sustainable construction project selection: an integrated FPP-FIS model. Journal of Civil Engineering and Management, 26(3), 247-258. https://doi.org/10.3846/jcem.2020.12183

Galende-Hernández, M., Menéndez, M., Fuente, M. J., \& SainzPalmero, G. I. (2018). Monitor-While-Drilling-based estimation of rock mass rating with computational intelligence: The case of tunnel excavation front. Automation in Construction, 93, 325-338. https://doi.org/10.1016/j.autcon.2018.05.019

Gou, L. F., \& Zhong, Y. (2019). A new fault diagnosis method based on attributes weighted neutrosophic set. IEEE Access, 7, 117740-117748.

https://doi.org/10.1109/ACCESS.2019.2936494

Hafezalkotob, A., Hafezalkotob, A., Liao, H. C., \& Herrera, F. (2020). Interval MULTIMOORA method integrating interval Borda rule and interval best-worst-method-based weighting model: Case study on hybrid vehicle engine selection. IEEE Transactions on Cybernetics, 50(3), 1157-1169. https://doi.org/10.1109/TCYB.2018.2889730

Hatefi, S. M., \& Tamošaitienè, J. (2019). An integrated fuzzy DEMATEL-fuzzy ANP model for evaluating construction projects by considering interrelationships among risk factors. Journal of Civil Engineering and Management, 25(2), 114-131. https://doi.org/10.3846/jcem.2019.8280

Hocine, A., Zhuang, Z. Y., Kouaissah, N., \& Li, D. C. (2020). Weighted-additive fuzzy multi-choice goal programming
(WA-FMCGP) for supporting renewable energy site selection decisions. European Journal of Operational Research, 285(2), 642-654. https://doi.org/10.1016/j.ejor.2020.02.009

Hosseini, S. T., Lale Arefi, S., Bitarafan, M., Abazarlou, S., \& Zavadskas, E. K. (2016). Evaluation types of exterior walls to reconstruct Iran earthquake areas (Ahar Heris Varzeqan) by using AHP and fuzzy methods. International Journal of Strategic Property Management, 20(3), 328-340. https://doi.org/10.3846/1648715x.2016.1190794

Huang, M., Zhang, X. L., Ren, R. X., Liao, H. C., Zavadskas, E. K., \& Antuchevičienè, J. (2020). Energy-saving building program evaluation with an integrated method under linguistic environment. Journal of Civil Engineering and Management, 26(5), 447-458. https://doi.org/10.3846/jcem.2020.12647

Ilbahar, E., Karaşan, A., Cebi, S., \& Kahraman, C. (2018). A novel approach to risk assessment for occupational health and safety using Pythagorean fuzzy AHP \& fuzzy inference system. Safety Science, 103, 124-136.

https://doi.org/10.1016/j.ssci.2017.10.025

Inti, S., \& Tandon, V. (2017). Application of fuzzy preferenceanalytic hierarchy process logic in evaluating sustainability of transportation infrastructure requiring multicriteria decision making. Journal of Infrastructure Systems, 23(4), 04017014. https://doi.org/10.1061/(ASCE)IS.1943-555X.0000373

Issa, U. H., Miky, Y. H., \& Abdel-Malak, F. F. (2019). A decision support model for civil engineering projects based on multi-criteria and various data. Journal of Civil Engineering and Management, 25(2), 100-113.

https://doi.org/10.3846/jcem.2019.7551

Jang, W., Lee, S. K., \& Han, S. H. (2018). Sustainable performance index for assessing the green technologies in urban infrastructure projects. Journal of Management in Engineering, 34(2), 04017056.

https://doi.org/10.1061/(ASCE)ME.1943-5479.0000582

Jato-Espino, D., Indacoechea-Vega, I., Gáspár, L., \& Castro-Fresno, D. (2018). Decision support model for the selection of asphalt wearing courses in highly trafficked roads. Soft Computing, 22(22), 7407-7421.

https://doi.org/10.1007/s00500-018-3136-7

Javadi, M., Saeedi, G., \& Shahriar, K. (2017). Developing a new probabilistic approach for risk analysis, application in underground coal mining. Journal of Failure Analysis and Prevention, 17(5), 989-1010. https://doi.org/10.1007/s11668-017-0325-0

Keshavarz-Ghorabaee, M., Amiri, M., Zavadskas, E. K., Turskis, Z., \& Antucheviciene, J. (2018). A dynamic fuzzy approach based on the EDAS Method for multi-criteria subcontractor evaluation. Information, 9(3), 68.

https://doi.org/10.3390/info9030068

Leśniak, A., Kubek, D., Plebankiewicz, E., Zima, K., \& Belniak, S. (2018). Fuzzy AHP application for supporting contractors' bidding decision. Symmetry, 10(11), 642. https://doi.org/10.3390/sym10110642

Liang, R., Dong, Z. J., Sheng, Z. H., Wang, X. Y., \& Wu, C. Z. (2017). Case study of selecting decision-making schemes in large-scale infrastructure projects. Journal of Infrastructure Systems, 23(4), 06017001. https://doi.org/10.1061/(ASCE) IS.1943-555X.0000364

Liao, H. C., \& Wu, X. L. (2020). DNMA: a double normalizationbased multiple aggregation method for multi-expert multicriteria decision making. Omega, 94, 102058. https://doi.org/10.1016/j.omega.2019.04.001

Liao, H. C., Xu, Z. S., \& Zeng, X. J. (2014). Distance and similarity measures for hesitant fuzzy linguistic term sets and their 
application in multi-criteria decision making. Information Sciences, 271, 125-142. https://doi.org/10.1016/j.ins.2014.02.125

Liao, H. C., Wu, X. L., Liang, X. D., Yang, J. B., Xu, D. L., \& Herrera, F. (2018). A continuous interval-valued linguistic ORESTE method for multi-criteria group decision making. Knowledge-Based Systems, 153, 65-77.

https://doi.org/10.1016/j.knosys.2018.04.022

Maghsoodi, A. I., \& Khalilzadeh, M. (2017). Identification and evaluation of construction projects' critical success factors employing fuzzy-TOPSIS approach. KSCE Journal of Civil Engineering, 22(5), 1593-1605.

https:/doi.org/10.1007/s12205-017-1970-2

Mahamadu, A. M., Manu, P., Mahdjoubi, L., Booth, C., Aigbavboa, C., \& Abanda, F. H. (2019). The importance of BIM capability assessment. Engineering, Construction and Architectural Management, 27(1), 24-48.

https://doi.org/10.1108/ECAM-09-2018-0357

Martin, H., Lewis, T. M., Petersen, A., \& Peters, E. (2017). Cloudy with a chance of fuzzy: building a multicriteria uncertainty model for construction project delivery selection. Journal of Computing in Civil Engineering, 31(1), 04016046.

https://doi.org/10.1061/(ASCE)CP.1943-5487.0000614

Mardani, A., Jusoh, A., \& Zavadskas, E. K. (2015). Fuzzy multiple criteria decision-making techniques and applications - Two decades review from 1994 to 2014. Expert Systems with Applications, 42(8), 4126-4148.

https://doi.org/10.1016/j.eswa.2015.01.003

Mazher, K. M., Chan, A. P. C., Zahoor, H., Khan, M. I., \& Ameyaw, E. E. (2018). Fuzzy integral-based risk-assessment approach for public-private partnership infrastructure projects. Journal of Construction Engineering and Management, 144(12), 04018111.

https://doi.org/10.1061/(ASCE)CO.1943-7862.0001573

Mi, X. M., Tang, M., Liao, H. C., Shen, W. J., \& Lev, B. (2019). The state-of-the-art survey on integrations and applications of the best worst method in decision making: Why, what, what for and what's next? Omega, 87, 205-225.

https://doi.org/10.1016/j.omega.2019.01.009

Mohandes, S. R., Sadeghi, H., Mahdiyar, A., Durdyev, S., Banaitis, A., Yahya, K., \& Ismail, S. (2020). Assessing construction labours' safety level: a fuzzy MCDM approach. Journal of Civil Engineering and Management, 26(2), 175-188.

https://doi.org/10.3846/jcem.2020.11926

Nyongesa, H. O., Musumba, G. W., \& Chileshe, N. (2017). Partner selection and performance evaluation framework for a construction-related virtual enterprise: a multi-agent systems approach. Architectural Engineering and Design Management, 13(5), 344-364.

https://doi.org/10.1080/17452007.2017.1324398

Omar, T., Nehdi, M. L., \& Zayed, T. (2017). Performance of NDT techniques in appraising condition of reinforced concrete bridge decks. Journal of Performance of Constructed Facilities, 31(6), 04017104.

https://doi.org/10.1061/(ASCE)CF.1943-5509.0001098

Osei-Kyei, R., \& Chan, A. P. C. (2017). Developing a project success index for public-private partnership projects in developing countries. Journal of Infrastructure Systems, 23(4), 04017028.

https://doi.org/10.1061/(ASCE)IS.1943-555X.0000388

Owusu, E. K., Chan, A. P. C., Hosseini, M. R., \& Nikmehr, B. (2020). Assessing procurement irregularities in the supplychain of Chanaian construction projects: A soft-computing approach. Journal of Civil Engineering and Management, 26(1), 66-82. https://doi.org/10.3846/jcem.2020.11659
Pang, Q., Wang, H., \& Xu, Z. S. (2016). Probabilistic linguistic term sets in multi-attribute group decision making. Information Science, 369, 128-143.

https://doi.org/10.1016/j.ins.2016.06.021

Patel, D. A., \& Jha, K. N. (2017). Developing a process to evaluate construction project safety hazard index using the possibility approach in India. Journal of Construction Engineering and Management, 143(1), 04016081.

https://doi.org/10.1061/(ASCE)CO.1943-7862.0001205

Plebankiewicz, E., \& Kubek, D. (2016). Multicriteria selection of the building material supplier using AHP and fuzzy AHP. Journal of Construction Engineering and Management, 142(1), 04015057. https://doi.org/10.1061/(ASCE)CO.1943-7862.0001033

Plebankiewicz, E., Meszek, W., Zima, K., \& Wieczorek, D. (2020). Probabilistic and fuzzy approaches for estimating the life cycle costs of buildings under conditions of exposure to risk. Sustainability, 12(1), 226. https://doi.org/10.3390/su12010226

RazaviAlavi, S., \& AbouRizk, S. (2017). Genetic algorithmsimulation framework for decision making in construction site layout planning. Journal of Construction Engineering and Management, 143(1), 04016084.

https://doi.org/10.1061/(ASCE)CO.1943-7862.0001213

Rezakhani, P., \& Maghiar, M. (2019). Fuzzy analytical solution for activity duration estimation under uncertainty. ASCEASME Journal of Risk and Uncertainty in Engineering Systems, Part A: Civil Engineering, 5(4), 04019014. https://doi.org/10.1061/AJRUA6.0001020

Rodríguez, R. M., Martinez, L., \& Herrera, F. (2012). Hesitant fuzzy linguistic term sets for decision making. IEEE Transactions on Fuzzy Systems, 20(1), 109-119. https://doi.org/10.1109/TFUZZ.2011.2170076

Satapathy, S., Kumar, S., Garanayak, A., \& Pani, A. (2018). An analysis of physical disorders of workers at construction site: a fuzzy-AHP ranking. International Journal of Business Excellence, 14(2), 212-239.

https://doi.org/10.1504/IJBEX.2018.089151

Smarandache, F. (2015). Symbolic neutrosophic theory. http://arxiv.org/abs/1512.00047v1

Song, X. L., Zhong, L., Zhang, Z., Xu, J. P., Shen, C., \& Peña-Mora, F. (2018). Multistakeholder conflict minimization-based layout planning of construction temporary facilities. Journal of Computing in Civil Engineering, 32(2), 04017080. https://doi.org/10.1061/(ASCE)CP.1943-5487.0000725

Taylan, O., Kabli, M. R., Porcel, C., \& Herrera-Viedma, E. (2017). Contractor selection for construction projects using consensus tools and big data. International Journal of Fuzzy Systems, 20(4), 1267-1281. https://doi.org/10.1007/s40815-017-0312-3

Tomczak, M., \& Rzepecki, L. (2017). Evaluation of supply chain management systems used in civil engineering. IOP Conference Series: Materials Science and Engineering, 245, 072005. https://doi.org/10.1088/1757-899X/245/7/072005

Utama, W. P., Chan, A. P. C., Zahoor, H., Gao, R., \& Jumas, D. Y. (2019). Making decision toward overseas construction projects. Engineering, Construction and Architectural Management, 26(2), 285-302. https://doi.org/10.1108/ECAM-01-2018-0016

Vo, K. D., Nguyen, P. T., \& Phan, P. T. (2018). Job performance factors of civil engineers in Vietnam. Journal of Mechanics of Continua and Mathematical Sciences, 14(5), 571-575. https://doi.org/10.26782/jmcms.2019.10.00041

Wallenius, J., Dyer, J. S., Fishburn, P. C., Steuer, R. E., Zionts, S., $\&$ Deb, K. (2008). Multiple criteria decision making, multiat- 
tribute utility theory: Recent accomplishments and what lies ahead. Management Science, 54(7), 1336-1349.

https://doi.org/10.1287/mnsc.1070.0838

Wang, T. K., \& Piao, Y. (2019). Development of BIM-AR-based facility risk assessment and maintenance system. Journal of Performance of Constructed Facilities, 33(6), 04019068. https://doi.org/10.1061/(ASCE)CF.1943-5509.0001339

Wieczorek, D., Plebankiewicz, E., \& Zima, K. (2019). Model estimation of the whole life cost of a building with respect to risk factors. Technological and Economic Development of Economy, 25(1), 20-38. https://doi.org/10.3846/tede.2019.7455

Wu, X. L., \& Liao, H. C. (2019). A consensus-based probabilistic linguistic gained and lost dominance score method. European Journal of Operational Research, 272, 1017-1027. https://doi.org/10.1016/j.ejor.2018.07.044

Xiao, Y., \& Zhang, C. H. (2016). A new method for financial decision making under intuitionistic linguistic environment. Economic Computation and Economic Cybernetics Studies and Research, 50(3), 303-318.

Yoon, J. H., \& Cha, H. S. (2018). Optimal FM strategy for commercial office buildings using fuzzy synthetic evaluation. Journal of Performance of Constructed Facilities, 32(3), 04018025. https://doi.org/10.1061/(ASCE)CF.1943-5509.0001176

Yu, Y., Darko, A., Chan, A. P. C., Chen, C., \& Bao, F. Y. (2018). Evaluation and ranking of risk factors in transnational public-private partnerships projects: Case study based on the intuitionistic fuzzy analytic hierarchy process. Journal of Infrastructure Systems, 24(4), 04018028. https://doi.org/10.1061/(ASCE)IS.1943-555X.0000448

Zadeh, L. A. (1965). Fuzzy sets. Information and Control, 8, 338353. https://doi.org/10.1016/S0019-9958(65)90241-X

Zavadskas, E., Antucheviciene, J., Vilutiene, T., \& Adeli, H. (2017). Sustainable decision-making in civil engineering, construction and building technology. Sustainability, 10(2), 14. https://doi.org/10.3390/su10010014

Zhang, L., Ding, L., Wu, X., \& Skibniewski, M. J. (2017). An improved Dempster-Shafer approach to construction safety risk perception. Knowledge-Based Systems, 132, 30-46.

https://doi.org/10.1016/j.knosys.2017.06.014

Zhao, X. J., Chen, L., Pan, W., \& Lu, Q. C. (2017). AHP-ANPfuzzy integral integrated network for evaluating performance of innovative business models for sustainable building. Journal of Construction Engineering and Management, 143(8), 04017054 . https://doi.org/10.1061/(ASCE)CO.1943-7862.0001348

Zolfaghari, S., \& Mousavi, S. M. (2018). Construction-project risk assessment by a new decision model based on De-Novo multi-approaches analysis and hesitant fuzzy sets under uncertainty. Journal of Intelligent \& Fuzzy Systems, 35(1), 639649. https://doi.org/10.3233/JIFS-162013

Zyoud, S. H., Kaufmann, L. G., Shaheen, H., Samhan, S., \& Fuchs-Hanusch, D. (2016). A framework for water loss management in developing countries under fuzzy environment: Integration of fuzzy AHP with fuzzy TOPSIS. Expert Systems with Applications, 61, 86-105.

https://doi.org/10.1016/j.eswa.2016.05.016 